Check for updates

Cite this: Chem. Sci., 2019, 10, 34

๑ All publication charges for this article have been paid for by the Royal Society of Chemistry

Received 25th September 2018 Accepted 3rd November 2018

DOI: $10.1039 / \mathrm{c} 8 \mathrm{sc} 04271 \mathrm{c}$

rsc.li/chemical-science

\section{En route to metal-mediated and metal-catalysed reactions in water}

\author{
Feng Zhou (D) and Chao-Jun Li (D) * \\ This perspective report presents the key approaches for the development of various organometallic \\ reactions in aqueous media. In view of future sustainability, the efficient use of natural resources, such as \\ renewable biomass-based feedstocks, constitutes an important aspect for sustainable chemical industry. \\ The exploration and discovery of efficient organometallic reactions or equivalents in water enrich the \\ toolbox of organic chemists for the direct conversion of biomass-derived feedstocks into high-valued \\ chemicals and the direct modification of biomolecules in their native aqueous environment, which \\ contributes to future sustainability.
}

\section{Introduction}

Carbon-carbon bond formation plays the central role in synthetic organic chemistry. For polar routes, such transformations necessarily involve carbon nucleophiles and electrophiles. ${ }^{1}$ One class of the most commonly used nucleophiles is organometallic compounds. Since the discovery of alkylzinc compounds by Frankland from the reaction of iodoalkanes with metallic zinc, ${ }^{2}$ organometallic reagents serving as nucleophiles for organic syntheses have been rapidly evolved both in scope and application. ${ }^{3-7}$ The early discoveries of Reformatsky, ${ }^{8}$ Barbier, ${ }^{9}$ Grignard, ${ }^{10}$ and Gilman ${ }^{11}$ are among the important milestones in the development of classical organometallic reactions. Subsequently, there have been great progresses in the use of alkali ${ }^{12}$ and other metals since the 1930s. Recently, organometallic reactions catalysed by transition metals have become increasingly important in the synthesis of organic molecules, ${ }^{13}$ underscored by three Nobel Prizes: for palladiumcatalysed cross-coupling in 2010, ${ }^{14-16}$ olefin metathesis in $2005^{17-19}$ and asymmetric catalysis in $2001^{20-22}$ within the last decade.

In spite of the enormous progress being made, there are obvious shortcomings for classical organometallic reactions in terms of chemical sustainability, such as the extensive use of organic solvents, stoichiometric metals, moisture and functional group intolerances, which are partially ascribed to the limitation of the historical development of classical reactions from fossil based feedstocks ${ }^{23}$ bearing no functional groups and being insoluble in water. Accordingly, classical organic reactions were intuitively developed in fossil originated organic solvents. With the increasing concerns of the depletion of nonrenewable fossil resources and the environmental

Department of Chemistry, FRQNT Center for Green Chemistry and Catalysis, McGill University, Montreal, Quebec H3A 0B8, Canada.E-mail: cj.li@mcgill.ca deterioration, ${ }^{24}$ developing products from renewable resources and improving resources/energy utilization efficiency are the key measures towards future chemical sustainability. ${ }^{25}$

Biomass, as a sustainable and renewable feedstock provided by nature could be a practical alternative towards future chemicals. ${ }^{26-28}$ In contrast to the fossil-based feedstocks, biomass-based ones are generally over-functionalized and often soluble or soluble after depolymerisation in water. As a result, further processing is required to adapt them to the reaction conditions that were initially developed for fossil-based classical organometallic reactions in organic solvents. One of the most common strategies for such purposes is the exhaustive protecting group manipulations, which in turn limiting the possibility of using water as solvent and leading to extra steps and waste etc. Conversely, exploration of organometallic reactions directly in water could be a possible solution in terms of various functional groups tolerance and direct chemical modification of biomolecules. Hence, exploring such fundamentally novel chemistry would potentially simplify chemical synthesis significantly, improve synthetic efficiency, provide valuable tools for chemical biology, and contribute to the future chemical sustainability ${ }^{29}$ with respect to atom-economy, ${ }^{30}$ the Efactor $^{31}$ and step-economy. ${ }^{32}$

\section{General design concept}

Most classical organometallic compounds are highly polarized as carbanions, which are also strong bases. Consequently, they are unstable towards active protons (moisture or functional groups) and must be synthesized/used under strictly anhydrous/aprotic conditions. Conceptually, the key to developing successful organometallic reactions in water (aqueous media) is to attenuate or prevent the protonation of carbonmetal bond once the organometallic species is generated (eqn (1)). 


$$
\mathrm{R}-\mathrm{MX} \stackrel{\mathrm{H}_{2} \mathrm{O}}{\longrightarrow} \mathrm{R}-\mathrm{H}+\mathrm{MX}(\mathrm{OH})
$$

There are several conceivable approaches to achieve this objective. The most straightforward approach is to tune the relative electronegativity ${ }^{33}$ between carbon and metal atoms to form the more covalent $\mathbf{C}-\mathbf{M}$ bond. A second approach is to design radical pathways, as the strong $\mathrm{O}-\mathrm{H}$ bond (enthalpy $436 \mathrm{~kJ} \mathrm{~mol}^{-1}$ ) is very difficult to break homolytically. The third approach is to mimic nature's lipid bilayer membrane ${ }^{34}$ by physically segregating and temporarily stabilizing the organometallic species from water via micelle formation using surfactants ${ }^{35}$ or on water strategy. ${ }^{36-38}$ The fourth approach is to bypass the stoichiometric organometallic reagents by transition-metal-catalysed organic transformations in water, such as via $\mathrm{C}-\mathrm{H}$ bond activation and hydrazone umpolung. ${ }^{39,40}$ This perspective article will illustrate these aspects using the classical nucleophilic additions as examples.

\section{Various approaches}

\section{Moving towards more covalent $\mathrm{C}-\mathrm{M}$ bond}

The main reason for the necessary anhydrous conditions in classical organometallic reactions was due to the highly polarized and reactive $\mathrm{C}-\mathrm{M}$ bonds towards water, ${ }^{3}$ especially the organometallic compounds of s-block elements. As $\mathrm{C}-\mathrm{M}$ bonds become more covalent, such as the organometallic compounds of group 14 and group 15, they have less carbanion character and thus are less prone to acidic proton and relatively more stable in aqueous media. Different from s-block and late pblock organometallic compounds, the ones from group 13 elements take up a special position within the main group due to their moderate reactivity towards water. ${ }^{41}$ Furthermore, certain classes of organometallics remain viable in the presence of water. For example, the preparation of arylmercuric chlorides in aqueous media has been known since $1905 .{ }^{42}$ In the 1960 's, tribenzylstannyl halide was prepared in large scale in water (Scheme 1). ${ }^{43-45}$ The Wurtz-type reductive coupling of allyl halides proceeded in aqueous alcohol. ${ }^{46}$ These reports opened up new perspectives regarding the metal-mediated organic reactions and it has been increasingly realized that these kinds of reactions can be conducted in water under special circumstances. Indeed, there has been great progress in this research area over the past decades, such as allylation, ${ }^{\mathbf{4 7 - 4 9}}$ allenylation, ${ }^{50,51}$ propargylation, ${ }^{52,53}$ benzylation, ${ }^{54}$ phenylation ${ }^{55,56}$ etc.

The most explored reaction is the allylation of carbonyls and other electrophiles with allyl halides mediated by various metals (Scheme 2), ${ }^{57}$ among which the use of indium to mediate

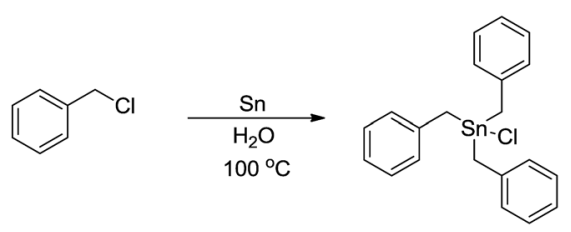

Scheme 1 Direct synthesis of tribenzylstannyl halide in water.

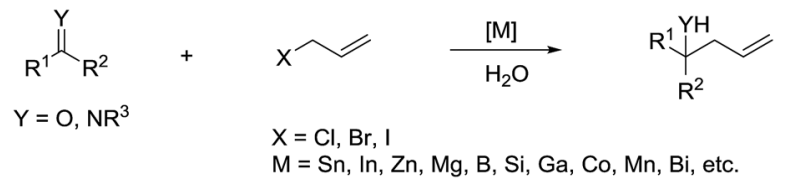

Scheme 2 Allylation of carbonyl and imine compounds.

the Barbier-Grignard-type reactions in water reported by $\mathrm{Li}$ and Chan received particular attention (Scheme 3$).^{48}$ This was attributed to the fact that on one hand, indium possesses the lowest first ionization potential among the metallic elements near it in the periodic table; and on the other hand, it does not form oxides readily in air and is not sensitive to boiling water or alkali. Consequently, indium was shown to be the most effective for such transformations in water, proceeding smoothly at room temperature without any promoter. This methodology has found wide applications in aqueous synthetic chemistry, ${ }^{58-61}$ particularly important in carbohydrate chemistry.

For example, Chan and $\mathrm{Li}^{62}$ reported a concise and stereoselective synthesis of (+)-3-deoxy-D-glycero-D-galacto-nonulosonic acid (KDN) from D-mannose (Scheme 4) and a formal synthesis ${ }^{63}$ of KDO (Scheme 5), whereas Whitesides reported the synthesis of $N$-acetyl-neuraminic acid (Scheme 6) ${ }^{64}$ and other sialic acid derivatives by the method. ${ }^{65,66}$ This chemistry has also been extended to six-carbon sialic acid derivatives by Chappell and Halcomb ${ }^{67}$ and the protocol has been further improved by Warwel and Fessner. ${ }^{68}$

Besides being used successfully in carbohydrates chemistry, the metal-mediated allylation has also been applied to the synthesis of other scaffolds such as 1,3-butadienes, ${ }^{69}$

$$
\mathrm{R}^{1} \stackrel{\mathrm{O}}{\mathrm{R}^{2}}+\underset{\mathrm{In} / \mathrm{H}_{2} \mathrm{O}}{\mathrm{X}=\mathrm{I}, \mathrm{Br}, \mathrm{Cl}} \underset{\mathrm{R}^{2}}{\stackrel{\mathrm{O}}{\mathrm{OH}}}
$$

Scheme 3 Indium-mediated carbonyl allylation in aqueous media.

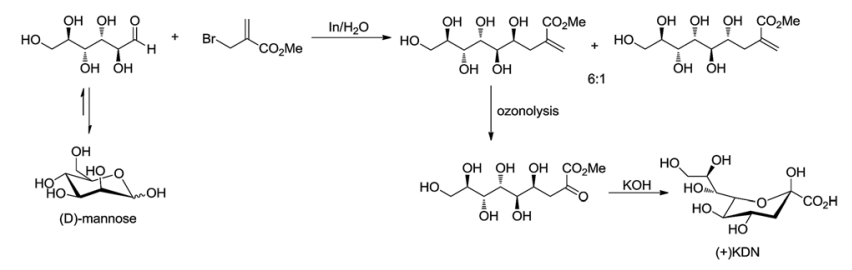

Scheme 4 Synthesis of (+)KDN.

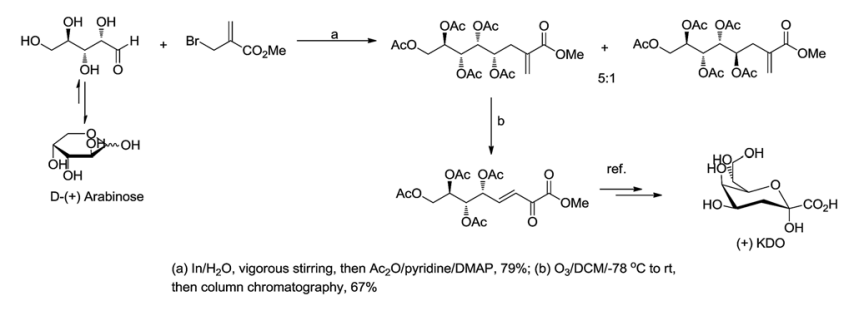

Scheme 5 Synthesis of (+)KDO. 

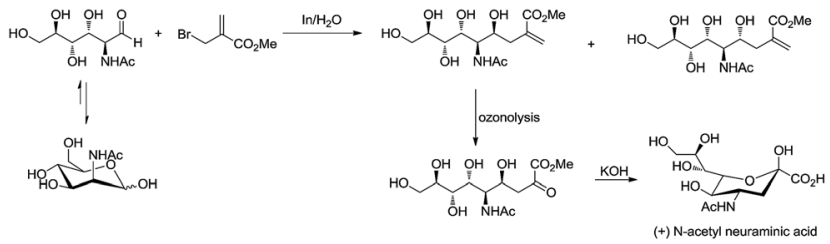

Scheme 6 Synthesis of (+)- $N$-acetyl neuraminic acid.

vinyloxiranes, 2-methylenetetrahydrofurans,$^{70}$ trimethylenemethane equivalent, ${ }^{71}$ cyclopentane derivatives. ${ }^{72}$ A carbocyclic ring enlargement methodology was also developed (Scheme 7), ${ }^{73,74}$ by using the indium-mediated Barbier-type reaction in water, in which 5-, 6-, 7-, 8-, and 12-membered rings are expanded by two carbon atoms into 7-, 8-, 9-, 10-, and 14-membered ring derivatives respectively. The use of water as a solvent was found to be critical for the success of the reaction and similar ring enlargement in organic solvents was not successful. Such a ring expansion strategy can also be applied to heterocyclic medium ring and ${ }^{75}$ one carbon-ring expansion. ${ }^{76}$

The diastereoselectivity of such reaction was studied in detail by Parquette and co-workers, and found that the free hydroxyl derivatives react with excellent diastereofacial control to give significantly heightened levels of $s y n-1,2$-diols and antidiols (Scheme 8). ${ }^{77}$ Relative reactivities were determined in the $\alpha$-series and the hydroxyl aldehyde proved to be the most reactive substrate. This reactivity ordering suggests that the selectivity stems from chelated intermediates. The rate acceleration observed in water can be heightened by initial acidification. Then they reported a variety of diastereoselective allylations in aqueous conditions and their synthetic applications such as a practical alternative to the Knoevenagel reaction of aliphatic aldehydes, the formation of $\alpha$-methylene- $\gamma$-lactones fused to medium and large rings and the intercalation of multiple carbon atoms between the carbonyls of $\alpha$-diketones. ${ }^{78}$

In 2002, Delgado and co-workers reported a Barbier-type diastereoselective allylation of $\alpha$-amino aldehydes with an enantiopure 2-sulfinylallyl building block in aqueous media mediated by zinc (Scheme 9). ${ }^{79}$ High levels of diastereoinduction can be achieved from $\alpha$-amino aldehydes configurationally related to natural $\alpha$-amino acids.

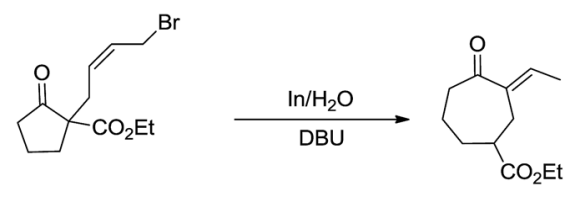

Scheme 7 In-mediated carbocyclic ring expansion in water.

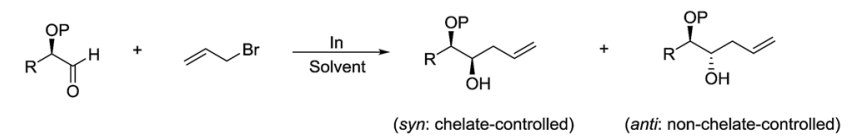

Scheme 8 In-mediated diastereoselective allylation of $\alpha$-oxy aldehydes in water.

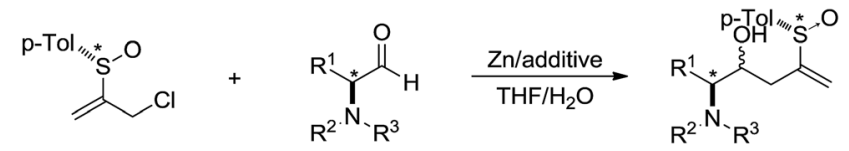

Scheme 9 Zinc-mediated Barbier-type diastereoselective allylation of $\alpha$-amino aldehydes with 2 -sulfinylallyl chloride in aqueous media.

The enantioselectivity of such reactions in water was also possible. In 1999, an enantioselective allylation reaction of aldehydes in an aqueous media using chiral pyridine bis(oxazoline) ligand was reported by Loh and co-workers (Scheme 10a). ${ }^{\mathrm{g0}}$ Subsequently, a $\mathrm{AgNO}_{3} /(S)$-Tol-BINAPcatalysed enantioselective allylation of aldehydes using allyltributylstannane was achieved by the same group (Scheme 10b). ${ }^{81}$ Later, they reported an enantioselective allylation of aldehyde catalysed by a moisture-tolerant chiral (S)-BINOLIn(III) complex. The allylation of a variety of aromatic, $\alpha, \beta$ unsaturated and aliphatic aldehydes resulted in both moderate to good yields and high enantioselectivities (Scheme 10c). ${ }^{82}$

In 2003, Kobayashi and co-workers reported a catalytic asymmetric allylation of aldehydes using allyltributyltin in aqueous media via the combination of cadmium bromide and chiral diamine ligands. Interestingly, these ligands were found to accelerate the reactions significantly (Scheme 11) ${ }^{83}$ Later, they reported an In-catalysed allylation of ketone with allyl

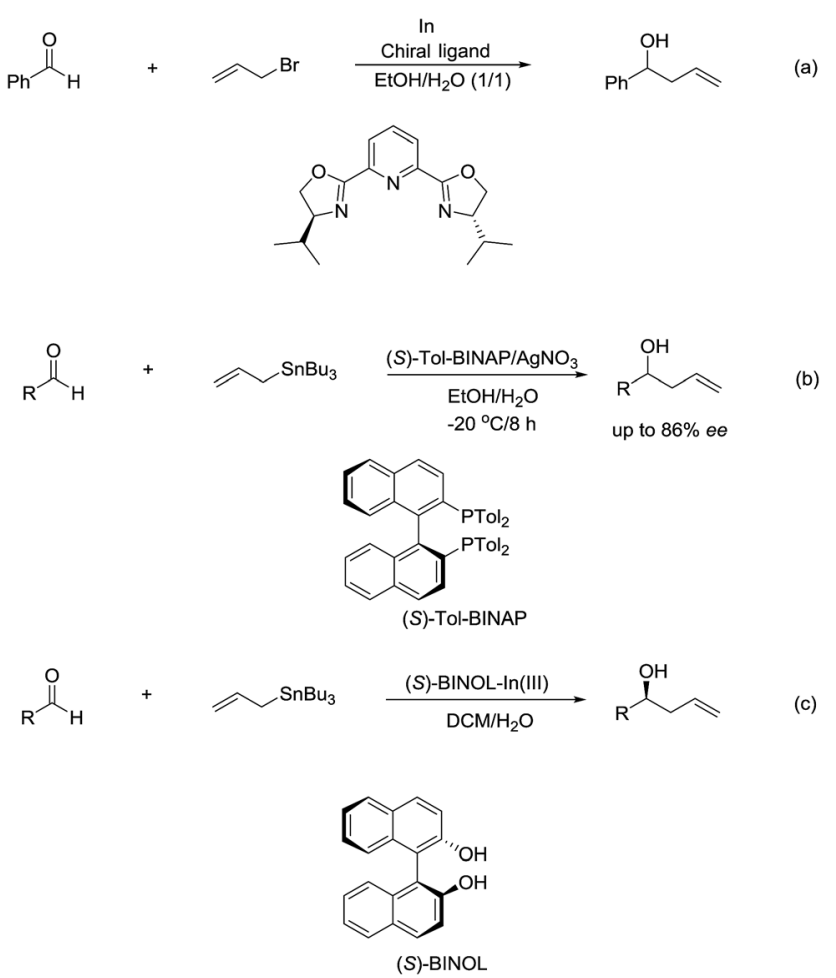

Scheme 10 (a) In-mediated enantioselective allylation of aldehydes using chiral pyridine bis(oxazoline) ligand; (b) $\mathrm{AgNO}_{3} /(\mathrm{S})$-Tol-BINAPcatalysed enantioselective allyation of aldehydes using allyltributylstannane in an aqueous media; (c) In(III)-(S)-BINOL complex catalysed enantioselective allylation of aldehyde using allyltributylstannane in an aqueous media. 


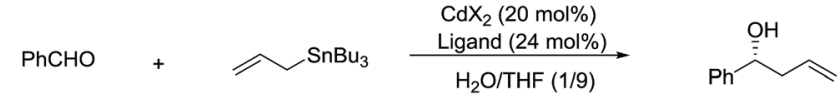

$\mathrm{Cd}\left(\mathrm{ClO}_{4}\right)_{2}, 30^{\circ} \mathrm{C}, 4 \mathrm{~h} ; 20 \%$ yield

$\mathrm{Cd}\left(\mathrm{ClO}_{4}\right)_{2}$, with ligand $\mathrm{a}, 30^{\circ} \mathrm{C}, 4 \mathrm{~h} ; 97 \%$ yield, $23 \%$ ee $(\mathrm{S})$

$\mathrm{CdBr}_{2}$ with ligand $\mathrm{b}, 0^{\circ} \mathrm{C}, 24 \mathrm{~h} ; 88 \%$ yield, $77 \%$ ee $(R)$
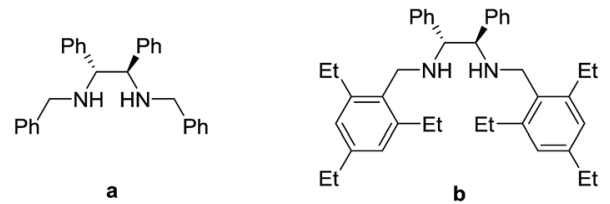

Scheme 11 Cd-catalysed asymmetric allylation of aldehyde using allyltributylstannane in an aqueous media.

boronates in water (Scheme 12) ${ }^{84}$ Preliminary asymmetric study using chiral bis-oxazoline ligand showed that a moderate enantioselectivity can be obtained.

In addition to allyl halides, structurally related propargyl halides are also effective for such type of reactions. In 1995, Issac and Chan reported their studies of the propargylation of aldehydes in aqueous medium mediated by indium (Scheme 13)..$^{52}$ They found that simple prop-2-yn-1-yl bromide reacted with both aliphatic and aromatic aldehydes in water to afford mainly the homopropargyl alcohols. In contrast, when propargyl bromide was $\gamma$-substituted, the coupling products were predominantly, or exclusively, the allenylic alcohols. Such couplings also proceed with $\alpha$-chloropropargyl phenyl sulfide. ${ }^{85}$

The indium-mediated coupling of propargyl bromide with a variety of imines and imine oxides afforded homopropargylamine derivatives in aqueous media under mild conditions (Scheme 14). ${ }^{86}$

Propargylation of glyoxylic oxime ether in the presence of a catalytic amount of palladium(0) complex and indium(I) iodide in aqueous media was also studied. ${ }^{87}$

The indium-mediated highly diastereoselective allenylation in aqueous medium was also highly successfully applied to the total synthesis of (+)-goniofufurone (Scheme 15). ${ }^{50,51}$

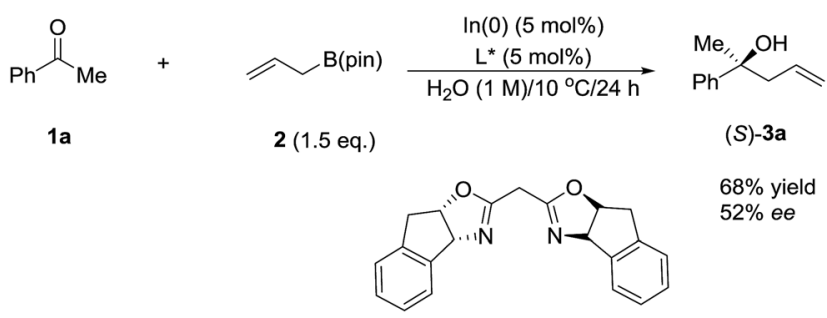

Scheme 12 In-catalysed asymmetric allylation of ketone using allyl boronate in water.

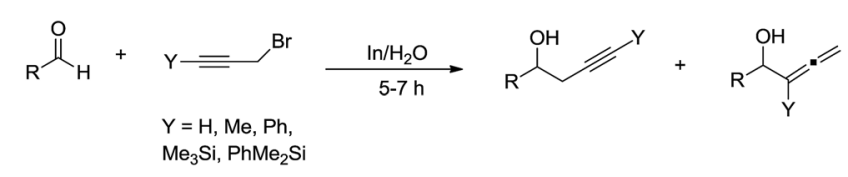

Scheme 13 In-mediated propargylation of aldehydes in water.

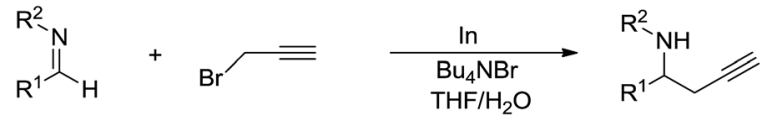

Scheme 14 In-mediated propargylation of imines.

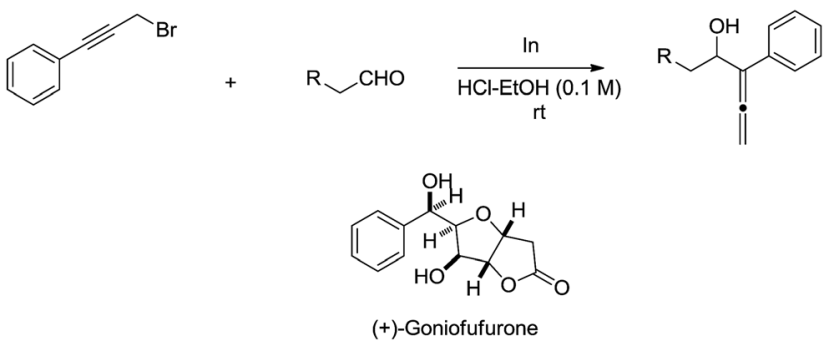

Scheme 15 Indium-mediated allenylation in aqueous media and its application to the synthesis of (+)-goniofufurone.

Benzyl halides and allyl(propargyl) halides are structurally similar but have distinctively different chemical reactivities in the aqueous Barbier-Grignard-type reactions. Although tribenzyl and dibenzyltin derivatives have been prepared in aqueous conditions since the 1960s, they do not add onto carbonyls, most likely because it is not possible to form a six-membered cyclic transition state with the carbonyl group in a 'twocomponent' fashion. Still, a zinc-mediated benzylation of carbonyl compounds in aqueous media was reported by Wang and co-workers in 2005 (Scheme 16). ${ }^{88}$

Compared with allyl and propargyl metal species, p-block aryl-metal (and metalloids) (aryl-tin, aryl-boron, aryl-bismuth, aryl-lead, and aryl-silicon) and vinyl-metal species are highly covalent and very unreactive by themselves. However, by utilizing a transition-metal catalyst, such aryl (and vinyl) derivatives become highly reactive, yet stable towards water and protonic functional groups. This strategy has been widely applied for their various cross-coupling reactions with organic halides.$^{89}$ By using a similar strategy, rhodium ${ }^{90-93}$ and palladium $^{94,95}$ catalysed arylation of carbonyls and (asymmetric) conjugate additions ${ }^{96-101}$ with aryl-metal reagents in water and under an air atmosphere are successful (Scheme 17a). ${ }^{55} \mathrm{~A}$ strong electronic effect on Rh-catalysed carbonyl additions and conjugated additions with various arylmetallic reagents was observed (Scheme 17b). ${ }^{56}$

\section{Moving towards more radical character}

Radicals are neutral species with one unpaired valence electron, which, in contrast to organic anions and cations, make them chemically "stable" towards water. Indeed, the aqueous radical

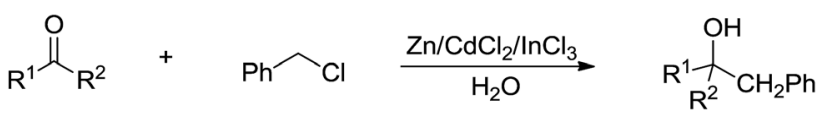

Scheme $16 \mathrm{Zn}$-mediated benzylation of carbonyl compounds in aqueous media in the presence of $\mathrm{CdCl}_{2}$ and $\mathrm{InCl}_{3}$. 


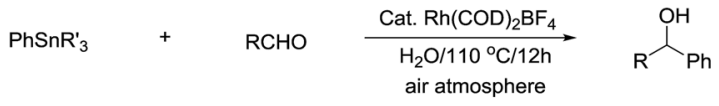

$$
\begin{aligned}
& (\mathrm{Ph})_{n} \mathrm{MX}_{\mathrm{m}}+\mathrm{ArCHO} \underset{\mathrm{H}_{2} \mathrm{O}}{\stackrel{\text { Cat. } \mathrm{Rh}(\mathrm{COD})_{2} \mathrm{BF}_{4}}{\longrightarrow}} \stackrel{\mathrm{Ar}_{\mathrm{Ph}}^{\mathrm{OH}}}{\lambda_{\mathrm{Ph}}} \\
& M=S n, B, S i, B i, P b
\end{aligned}
$$

Scheme 17 (a) Rh-catalysed carbonyl phenylation in water; (b) the electronic effect on Rh-catalysed carbonyl additions with arylmetallic reagents.

chemistry predominates in biological processes. ${ }^{\mathbf{1 0 2 , 1 0 3}}$ As radicals are nonpolar, their additions to $\mathrm{C}=\mathrm{C}$ bonds were first realized in water. In 1998, Oshima and co-workers reported that the $\mathrm{Et}_{3} \mathrm{~B}$-induced atom transfer radical cyclization of allyl iodoacetate proceeded much more smoothly in water at ambient temperature than in benzene or hexane (Scheme 18a). ${ }^{\mathbf{1 0}}$ Treatment of the allylic iodoacetate in water with $\mathrm{Et}_{3} \mathrm{~B}$ (metalloid) at room temperature for $3 \mathrm{~h}$ provided $\beta$-iodomethyl- $\gamma$-butyrolactone in $67 \%$ yield. In contrast, in benzene the desired product was not obtained at all and oligomeric by-products were formed.

The remarkable solvent effect of water was also observed in the case of medium and large ring construction. For example, Oshima and co-workers reported an intramolecular cyclization mediated by $\mathrm{Et}_{3} \mathrm{~B}$ in water provided the 9-membered lactone in $69 \%$ yield (Scheme 18b). The same reaction carried out in benzene afforded much inferior yield.$^{105}$ Although the exact role of water was not clear at that stage, a hydrogen bonding between water and the carbonyl oxygen could be formed to facilitate the abstraction of iodine, generating the (alkoxycarbonyl)methyl radical. Hydrophobic interaction may also accelerate the cyclization.

With regard to metal-mediated conjugate additions involving alkyl groups, Luche and coworkers reported that alkyl halides in the presence of zinc-copper couple reacted smoothly with conjugated carbonyl compounds and nitriles to give 1,4addition products in good yields under sonication conditions in aqueous conditions (Scheme 19a). ${ }^{\mathbf{1 0 6 - 1 0 8}}$ A moderate diastereoselectivity was obtained in those reactions where a mixture of

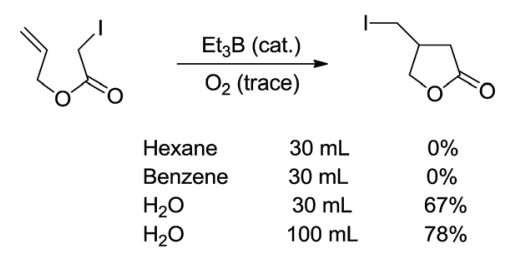

(a)<smiles>C[P+]([O-])(/C=C\P)c1ccccc1</smiles>

$$
\underset{\mathrm{RX}, \mathrm{EtOH} / \mathrm{H}_{2} \mathrm{O}, \mathrm{rt}}{\stackrel{\mathrm{Zn}(\mathrm{Cu}),()))))}{\longrightarrow}}
$$

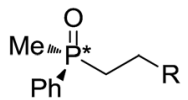

Scheme 20 Zinc-copper couple-mediated conjugate addition of alkyl halides to vinylphosphine oxides in aqueous media.

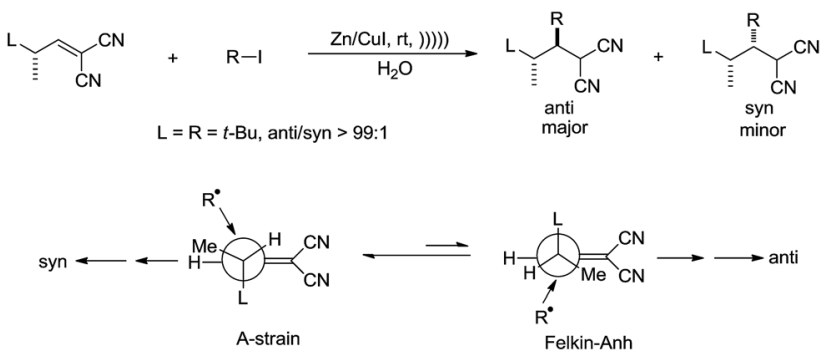

Scheme 21 Zinc-copper couple-mediated conjugate addition of alkyl halides and electron-deficient alkenes in water. 


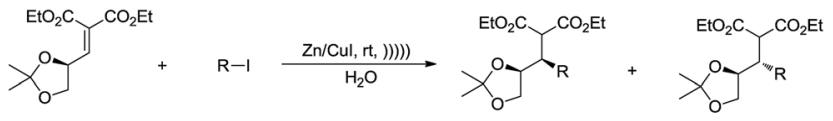

up to $99 \%$ yield and $88: 12$ syn/anti

Scheme 22 Zinc-copper couple-mediated diastereoselective addition of alkyl iodides and $\alpha, \beta$-unsaturated compounds in water.

prevent the more facile reversed reaction to break the $\mathrm{C}-\mathrm{C}$ bonds of the radical addition intermediate. One approach is via the stabilization of the radical. Thus, in 2002, $\mathrm{Li}$ and co-workers reported a zinc-mediated conjugate addition reaction of alkyl halides to $\alpha$-phthalimidoacylate derivatives and nucleophilic addition to imines for the efficient synthesis of $\alpha$-amino acid derivatives and amines in the presence of $\mathrm{NH}_{4} \mathrm{Cl}$ in water (Scheme 23). Notably, no reaction was observed in absence of water. ${ }^{116}$

It is noteworthy that $\mathrm{Li}$ and co-workers also reported a magnesium-mediated Barbier-type allylation of aldehyde using water as a sole solvent, which proceeds most likely via a radical process on the metal surface (Scheme 24). ${ }^{117}$

In 2002, Naito and co-workers reported an intermolecular alkyl radical addition to imine derivatives and electron-deficient $\mathrm{C}-\mathrm{C}$ double bond in aqueous media by using indium as a singleelectron-transfer radical initiator (Scheme 25). ${ }^{118}$ The one-pot reaction provided a convenient method for preparing $\alpha$-amino acids.

In 2003, they reported an indium-mediated cascade reaction, in which the addition-cyclization-trapping sequences efficiently generated the cyclized products in aqueous media (Scheme 26). ${ }^{119}$ The substrates bearing vinylsulfonamide and hydrazone proceeded smoothly in aqueous media to provide the functionalized cyclic products.

For the even more challenging Barbier-Grignard-type carbonyl alkylation using unactivated alkyl halides in water,<smiles>C=C(C(=O)OCC)N1C(=O)c2ccccc2C1=O</smiles>
$\underset{\mathrm{Zn} / \mathrm{aq} \cdot \mathrm{NH}_{4} \mathrm{Cl} / \mathrm{rt}}{\longrightarrow}$<smiles>[R]CC(C(=O)O[R])N1C(=O)c2ccccc2C1=O</smiles><smiles>[R]C=[NH2+]</smiles>

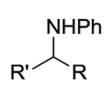

$\begin{array}{ll}\mathrm{R}=\mathrm{t}-\mathrm{Bul}, \mathrm{R}^{\prime}=\mathrm{Ph} & 70 \% \\ \mathrm{R}=\mathrm{t}-\mathrm{Prl}, \mathrm{R}^{\prime}=\mathrm{Ph}, & 60 \%\end{array}$ $\mathrm{R}=\mathrm{t}-\mathrm{Prl}, \mathrm{R}^{\prime}=0$ - $\mathrm{HOPh} 55 \%$

Scheme 23 Zinc-mediated conjugate addition of alkyl halides to $\alpha$ phthalimidoacylate and imine derivatives in aqueous media.

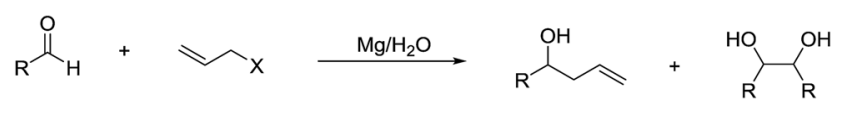

Scheme 24 Barbier-Grignard allylation of aldehydes with magnesium in water.

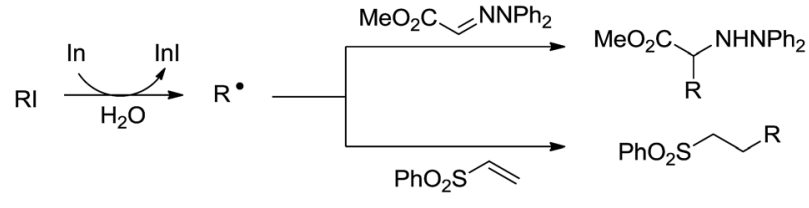

Scheme 25 In-mediated alkyl radical addition to imine and phenyl vinyl sulfone derivatives in aqueous media.

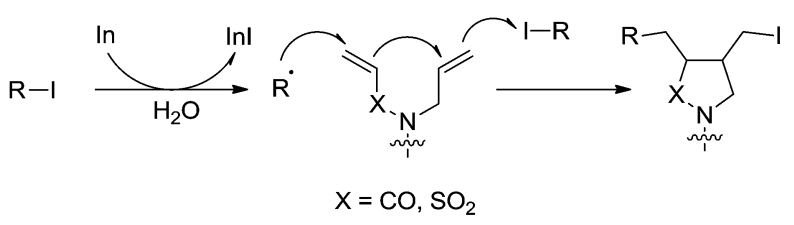

Scheme 26 Indium-mediated radical addition-cyclization-trapping cascade reaction in aqueous media.

in absence of radical stabilization, the "reductive Lewis acid" concept was used by Li and co-workers successfully, in which conceptually the addition is accompanied by reduction and "free radical intermediate" is not "free" during the reaction progress (Scheme 27). ${ }^{120}$

In 2008, Loh and co-workers further developed this BarbierGrignard-type alkylation reaction of aldehydes including aliphatic version using unactivated alkyl halides in water catalysed by In/CuI or In/AgI catalysis (Scheme 28). ${ }^{121}$ The reactions proceeded more efficiently in water than in organic solvent.

Another type of reactions is the metal-mediated Reformatsky-type reaction. The reaction of a metal with an $\alpha$ halogen carbonyl compound would generate an organometallic intermediate that can equilibrate between the carbanion form and the enolate form. Like the case of allyl and propargyl, the enolate form would allow the reaction to proceed through a sixmembered cyclic transition state and thus could be energetically favorable. Indeed, the reaction of an $\alpha$-halogen carbonyl compound with an aldehyde in the presence of zinc, tin, or indium in water provided a direct cross-aldol reaction product (Scheme 29). ${ }^{122,123}$ While a direct Reformatsky-type reaction occurred in low yields in the case of aromatic aldehydes were

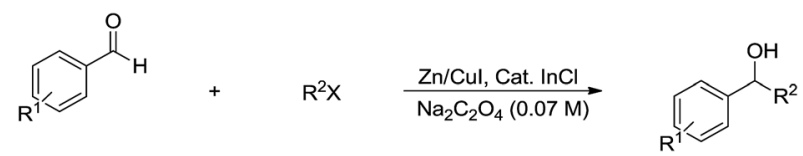

Scheme 27 Zinc-mediated Barbier-Grignard-type carbonyl alkylation in water.

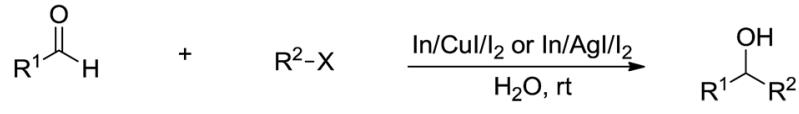

$$
\begin{aligned}
& \mathrm{R}^{1}=\text { aryl, alkyl } \\
& \mathrm{R}^{2}=\text { alkyl }
\end{aligned}
$$

Scheme $28 \mathrm{In} / \mathrm{Cul}$ or In/Agl-mediated alkylation of carbonyls in water. 


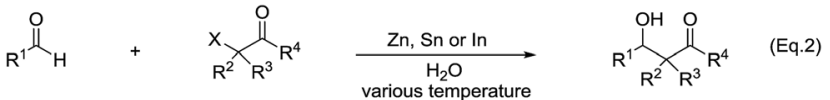

Scheme 29 Zn, Sn and In-mediated direct cross-aldol reactions of aldehydes and $\alpha$-halogen carbonyls.

used in water mediated by zinc. ${ }^{124}$ Later Lee and co-workers reported that the reactions of aldehydes or ketones with ethyl bromoacetate in the presence of indium promoted by ultrasound afforded $\beta$-hydroxyesters in good to excellent yields under mild conditions. ${ }^{125}$ Bieber and co-workers found that even catalytic amounts of benzoyl peroxide or peracids can greatly enhance the reactions of bromoacetates and aromatic aldehydes, giving satisfactory yields. A radical chain mechanism, initiated by electron abstraction from the organometallic Reformatsky reagent, was proposed (Scheme 30). ${ }^{126}$

The indium-mediated aqueous Reformatsky reaction was successfully applied to the synthesis of $\alpha, \alpha$-difluoro- $\beta$-hydroxy ketones by Welch and co-workers in 2001 (Scheme 31). ${ }^{127}$

\section{Via temporarily stabilization (surfactant) or on water strategy}

One strategy that nature frequently adopts to perform reactions in aqueous media is encapsulation via lipid bilayer membranes. ${ }^{34}$ Chemists, in turn, have developed surfactants that can be self-assembled in water to form micelles, ${ }^{128}$ which provide the lipophilic interior to serve, in essence, as the solvent for catalysis. Organic solutes interact with micelles according to their polarity: non-polar solutes are encapsulated in the interior

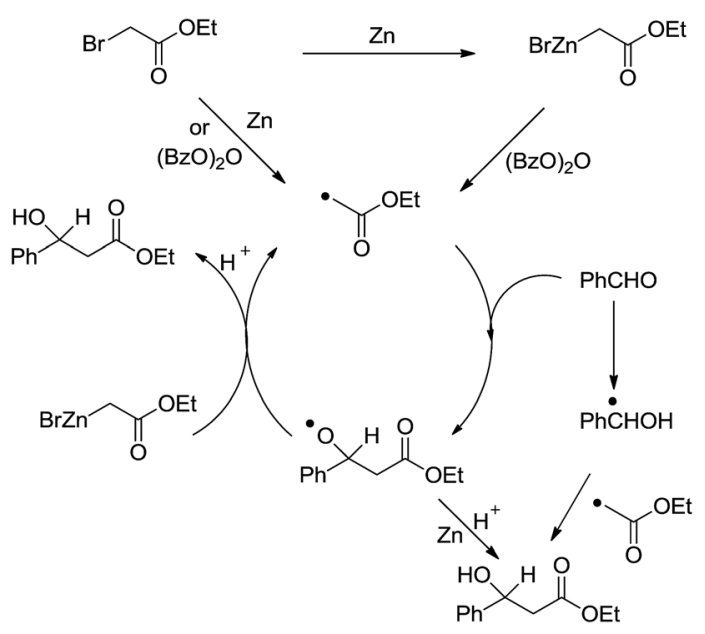

Scheme 30 Zinc-mediated Reformatsky-type reaction of bromoacetates and aromatic aldehydes and the proposed radical chain mechanism.

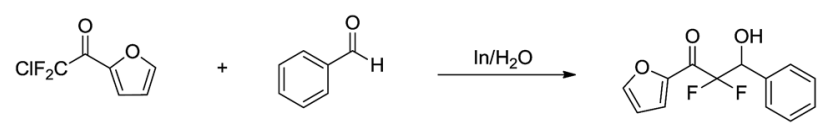

Scheme 31 In-mediated synthesis of $\alpha, \alpha$-difluoro- $\beta$-hydroxy ketones in water. of the micelle, while polar solutes locate themselves at the surface of the micelle and moderately polar molecules would be positioned closer to the polar surface. This compartmentalization of solutes lays the foundation and is responsible for many organic reactions in aqueous media, particularly assisting with organometallic processes, as the lipophilic interior of the surfactants provides the hydrophobic area to temporarily stabilize polar carbon-metal bond and facilitate the chemical transformation, such as in oxidation, reduction and $\mathrm{C}-\mathrm{C}$ coupling reactions. ${ }^{129}$

Recently, the application of surfactants for aqueous catalysis has been demonstrated in the development of catalytic organometallic reactions in water. For example, in 2004, Kobayashi and co-workers reported a Zn-mediated enantio and diastereoselective, stereospecific Mannich-type reaction in water, in which the surfactant CTAB (cetyltrimethylammonium bromide) significantly improved the yield (Scheme 32). ${ }^{130}$

In 2012, Lipshutz and co-workers reported a coppercatalysed conjugate addition of alkyl halides to enones mediated by zinc in aqueous media using TPGS-750-M as surfactant (Scheme 33). ${ }^{131}$ Various cross-coupling reactions catalysed by transition metals in aqueous media using surfactants were also reported by his group. ${ }^{132,133}$

In 2014, $\mathrm{Li}$ and co-workers reported the $\mathrm{Rh}$-catalysed and $\mathrm{Zn}$ mediated Barbier-Grignard-type arylation of aldehydes using unactivated aryl iodides in water, in which the organometallic species could be temporarily stabilized by encapsulation into the lipophilic interior of the surfactant BrijC10 (Scheme 34). ${ }^{134}$

In 2018, Lipshutz and co-workers developed an environmentally responsible, mild method for the synthesis of functionalized 1,3-butadienes via Pd-catalyzed cross-coupling of substituted allenic esters in water in the presence of the surfactant TPGS-750-M (Scheme 35$){ }^{135}$ Various sp-sp ${ }^{2}, \mathrm{sp}^{2}-\mathrm{sp}^{2}$, and $\mathrm{sp}^{2}-\mathrm{sp}^{3}$ coupling reactions were realized and these transformations tolerated broad functional groups.

As for the reactivity of polar organometallic compounds on water, recently Capriati and co-workers reported the nucleophilic addition of Grignard reagents and lithium reagents to $\gamma$ -

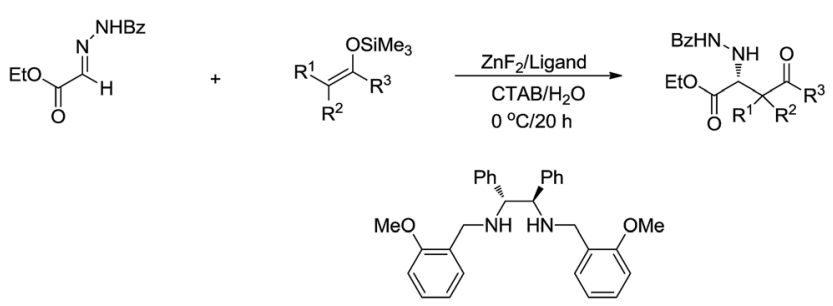

Scheme 32 Zinc-mediated asymmetric Mannich-type reactions in water using $C T A B$ as surfactant.

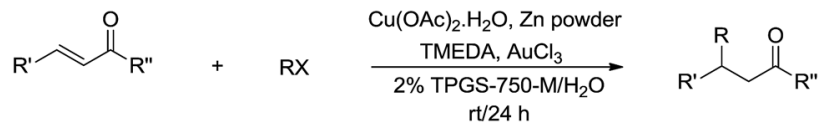

Scheme $33 \mathrm{Cu}$-catalysed and zinc-mediated conjugate additions of alkyl halides to enones in aqueous media using TPGS-750-M as surfactant. 


$$
\text { 奋 }
$$

Scheme 34 Rh-catalysed and Zn-mediated Barbier-Grignard-type arylation of aldehydes in water using BrijC10 as surfactant.

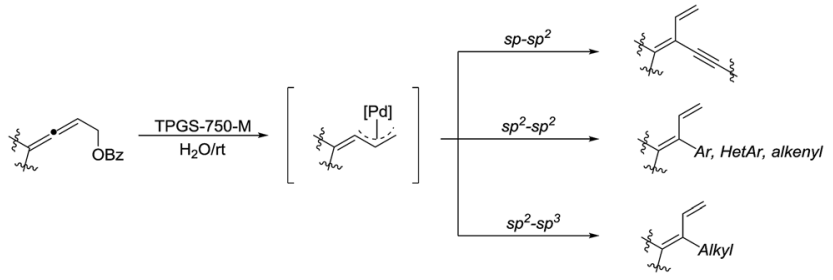

Scheme 35 Pd-catalysed cross-coupling of substituted allenic esters for the synthesis of functionalized 1,3-butadienes in water in the presence of the surfactant TPGS-750-M.

chloroketone on water at room temperature and under air for efficient formation of THF derivatives, in which water may play an important role as demonstrated by the solvent isotope effect and the control experiments that indicate the strong intermolecular hydrogen bonds jointly with trans-phase H-bonding with the substrate, thus (a) shielding the organometallic reagent from competitive protonolysis processes and (b) activating the carbonyl derivative towards nucleophilic addition (Scheme 36a). ${ }^{136}$ Later, they further developed the nucleophilic additions of organolithium and organomagnesium reagents to imines and nitriles using bulk water as a privileged reaction medium, working under air, at room temperature, with vigorous stirring (Scheme 36b). ${ }^{137}$ The significant solvent $\mathrm{D} / \mathrm{H}$ isotope effect observed for the on-water nucleophilic additions of organolithium compounds to imines suggests the on-water catalysis arises from proton transfer across the organic-water

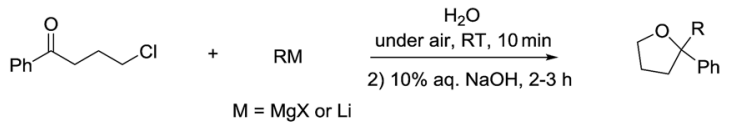

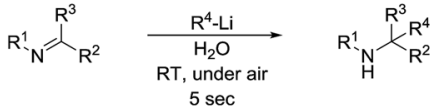

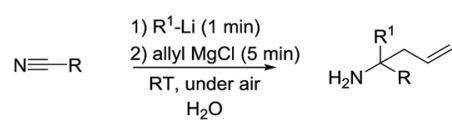

Scheme 36 (a) Formation of THF derivatives via nucleophilic additions of Grignard reagents to $\gamma$-chloroketone using on water strategy; (b) on-water addition of organolithium and organomagnesium reagents to imines and nitriles. interface. The strong intermolecular hydrogen bonds between water molecules may play a key role in disfavouring protonolysis, which occurs extensively in other protic media such as methanol. ${ }^{138,139}$

\section{Bypass stoichiometric reagents}

Via $\mathbf{C}-\mathbf{H}$ bond activation. The rising of green chemistry raises the awareness of atom economic and environmentally friendly method development. ${ }^{140}$ In this context, a large number of highly efficient and selective reaction systems have been developed, in which $\mathrm{C}-\mathrm{H}$ activation catalysed by transition metals is undoubtedly one of the fastest growing areas. ${ }^{141-143} \mathrm{In}$ view of both synthetic efficiency and future chemical sustainability, the development of the organometallic reactions in water via $\mathrm{C}-\mathrm{H}$ bond activation, generating a transient $\mathrm{C}-\mathrm{M}$ based intermediate that quickly reacts with electrophiles rather than water in absence of stoichiometric organometallic reagents, becomes attractive. ${ }^{144}$

In the past two decades, there have been great advances in aqueous $\mathrm{C}-\mathrm{H}$ bond activation catalysed by transition metals. Since $\mathrm{C}(\mathrm{sp})-\mathrm{H}$ bonds are the most acidic, hence the easiest to activate in water. In 2002, $\mathrm{Li}$ and co-workers reported that a bimetallic $\mathrm{Ru}$-In catalytic system could catalyse alkynylation of aldehydes in water (Scheme 37). ${ }^{145}$

Then, by using $\mathrm{Cu} / \mathrm{Ru}$ or $\mathrm{Cu} /$ pyridine-oxazoline catalyst, they succeeded the addition and asymmetric addition of arylacetylenes to imines to form propargylamines in excellent yields and enantioselectivity in water (Scheme 38). ${ }^{146,147}$ Furthermore a series of transition-metal-catalysed $\mathrm{C}(\mathrm{sp})-\mathrm{H}$ bond activation reactions in water were reported by his group. ${ }^{148,149}$

For the less acidic $\mathrm{C}\left(\mathrm{sp}^{2}\right)-\mathrm{H}$ bonds, one strategy to facilitate their reaction in water is via chelation. In 2010, Dixneuf and coworkers reported a Ru-catalysed and pyridine-directed $\mathrm{C}\left(\mathrm{sp}^{2}\right)-\mathrm{H}$ bond activation in water for efficient ortho-phenylation (Scheme 39). ${ }^{150}$ The selectivity of mono-phenylation and bisphenylations was found to be better in water than in organic solvent.

In 2012, Ackermann and co-workers developed the Rucatalysed tandem cyclization of aniline derivative and alkyne

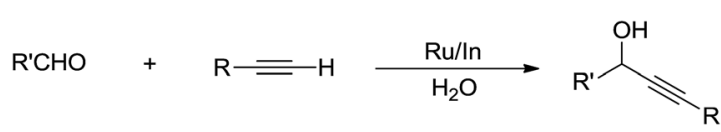

Scheme 37 Ru/In co-catalysed alkynylation of aldehydes in water

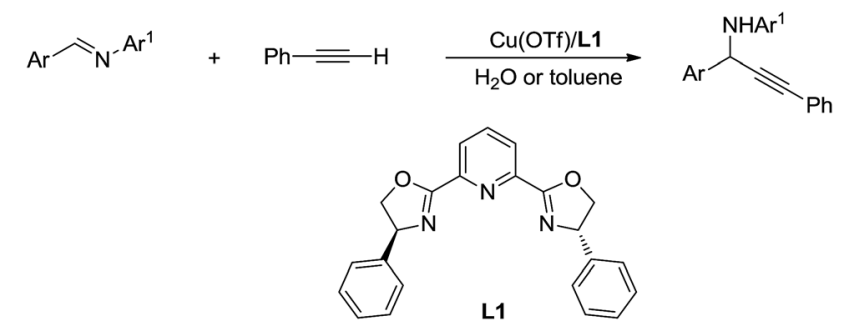

Scheme $38 \mathrm{Cu}$ /pyridine-oxazoline catalysed asymmetric addition of phenylacetylene to imine in water via $\mathrm{C}(\mathrm{sp})-\mathrm{H}$ activation. 


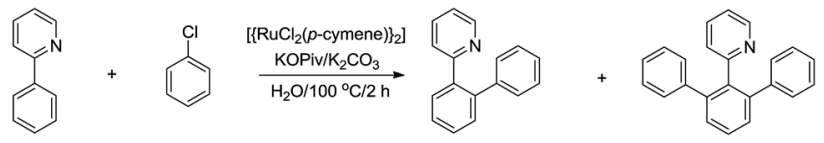

Scheme 39 Ru-catalysed ortho-phenylation in water via $\mathrm{C}\left(\mathrm{sp}^{2}\right)-\mathrm{H}$ bond activation.

for efficient indole synthesis via $\mathrm{C}\left(\mathrm{sp}^{2}\right)-\mathrm{H}$ bond activation in water (Scheme 40). ${ }^{151}$

In 2014, Loh and co-workers presented the Rh-catalysed and pyrimidine-directed 2-phenylation of indole derivatives via $\mathrm{C}\left(\mathrm{sp}^{2}\right)-\mathrm{H}$ bond activation in water using trimethoxyphenylsilane as phenylation reagent (Scheme 41). ${ }^{152}$ In 2015, Li and co-workers reported the Rh-catalysed homo-coupling of aryl carboxylic acid in water via two-fold $\mathrm{C}\left(\mathrm{sp}^{2}\right)-\mathrm{H}$ bond activation using $\mathrm{MnO}_{2}$ as terminal oxidant (Scheme 42). ${ }^{153}$

Such a chelation strategy can also be applied towards the least acidic $\mathrm{C}\left(\mathrm{sp}^{3}\right)-\mathrm{H}$ bonds. For example, in 2014, Chen and coworkers reported a Pd-catalysed $N$-quinolylcarboxamide directed $\beta$-arylation of alanine at room temperature via $\mathrm{C}\left(\mathrm{sp}^{3}\right)-$ $\mathrm{H}$ bond activation, in which water is used as a co-solvent (Scheme 43). ${ }^{154}$ This method provided a convenient approach for the synthesis of both natural and unnatural aromatic $\alpha$ amino acids.

In 2015, Rao and coworkers reported the Pd-catalysed $\beta$ $\mathrm{C}\left(\mathrm{sp}^{3}\right)-\mathrm{H}$ bond oxidation of amides using 8 -aminoquinoline as directing group in water (Scheme 44). ${ }^{155}$ Interestingly, the isotope labelling experiment indicates that the oxygen originates from water.

An alternative strategy for the $\mathrm{C}\left(\mathrm{sp}^{3}\right)-\mathrm{H}$ bonds activation is via radical process. In $2008, \mathrm{Li}$ and co-workers reported a direct addition of cycloalkanes to imines mediated by peroxide and

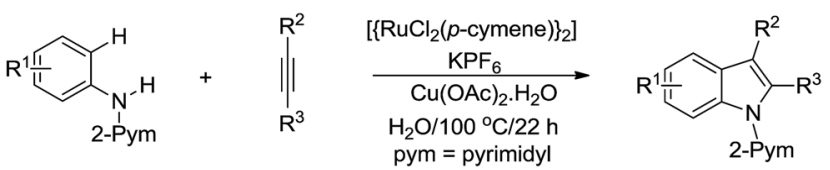

Scheme 40 Ru-catalysed tandem cyclization of aniline derivative and alkyne for indole synthesis in water via $\mathrm{C}\left(\mathrm{sp}^{2}\right)-\mathrm{H}$ bond activation.
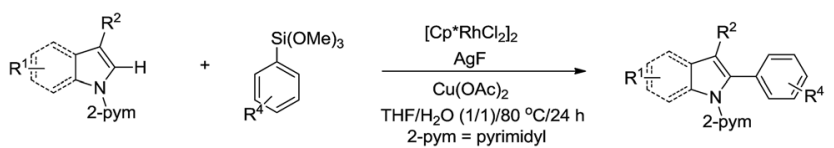

Scheme 41 Rh-catalysed 2-phenylation of indole derivatives in water via $\mathrm{C}\left(\mathrm{sp}^{2}\right)-\mathrm{H}$ bond activation.
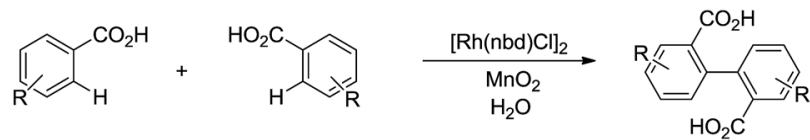

Scheme 42 Rh-catalysed homo-coupling of aryl carboxylic acid in water via two-fold $\mathrm{C}\left(\mathrm{sp}^{2}\right)-\mathrm{H}$ bond activation.

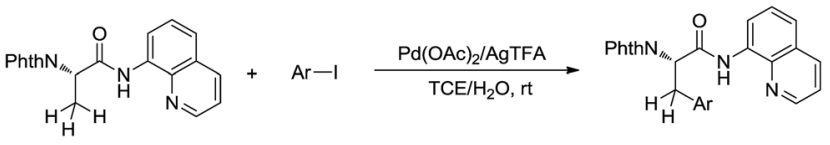

Scheme $43 \mathrm{Pd}$-catalysed $N$-quinolylcarboxamide directed $\beta$-arylation of alanine at room temperature via $\mathrm{C}\left(\mathrm{sp}^{3}\right)-\mathrm{H}$ bond activation using water as a co-solvent.

$$
\begin{aligned}
& \underset{\substack{\mathrm{Cyclic}\left(\mathrm{IIII)-OH} \\
\mathrm{H}_{2} \mathrm{O}\right.}}{\mathrm{Pd}(\mathrm{OAc})_{2}} \\
& \text { Cyclic I(III)-OH = }
\end{aligned}
$$

Scheme $44 \mathrm{Pd}$-catalysed $\beta-\mathrm{C}\left(\mathrm{sp}^{3}\right)-\mathrm{H}$ bond oxidation of amides using 8 -aminoquinoline as directing group in water.

the reaction tolerates a wide range of functionalities as well as aqueous conditions (Scheme 45). ${ }^{156}$

Via hydrazone umpolung. Umpolung is a phenomenon in which the polarity of a functional group is reversed. ${ }^{157,158}$ This opens up reactions on a functional group which is otherwise not possible. In nature, numerous enzymes such as acetohydroxy acid pseudoephedrine synthase (AHAS) catalyse both nucleophilic acylation and benzoin condensation reactions in aqueous media via umpolung strategy, in which a cofactor thiamine pyrophosphate (TPP) facilitates the catalytic function of these enzymes (Scheme 46). ${ }^{159-161}$ Inspired by the biocatalytic methods that use enzymes as catalysts for various $\mathrm{C}-\mathrm{C}$ bond forming reactions, chemists have successfully developed numerous $\mathrm{C}-\mathrm{C}$ forming reactions based on umpolung with carbonyls as acyl anion equivalents. Most of those reactions were catalysed by either $N$-heterocyclic carbene (NHC) or cyanide ion. ${ }^{\mathbf{1 6 2 , 1 6 3}}$ Related to organometallic reactions, one attractive approach is the metal-catalysed umpolung chemistry

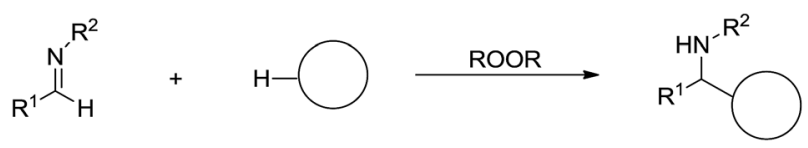

Scheme 45 The peroxide-mediated direct addition of cycloalkanes to imines.
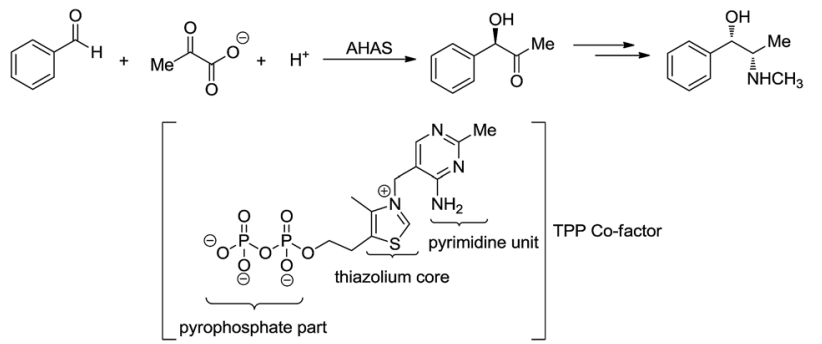

Scheme 46 AHAS catalysed acyloin condensation and the synthesis of ephedrine. 


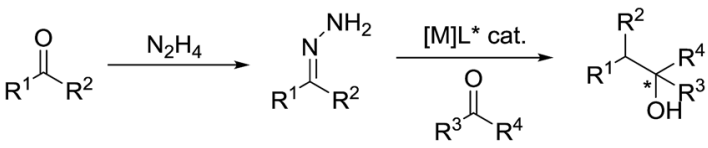

Cat., catalytic; $L^{*}$, chiral ligands. ${ }^{*}$, stereogenic centres.

Scheme 47 Metal-catalysed umpolung chemistry via hydrazone intermediate.

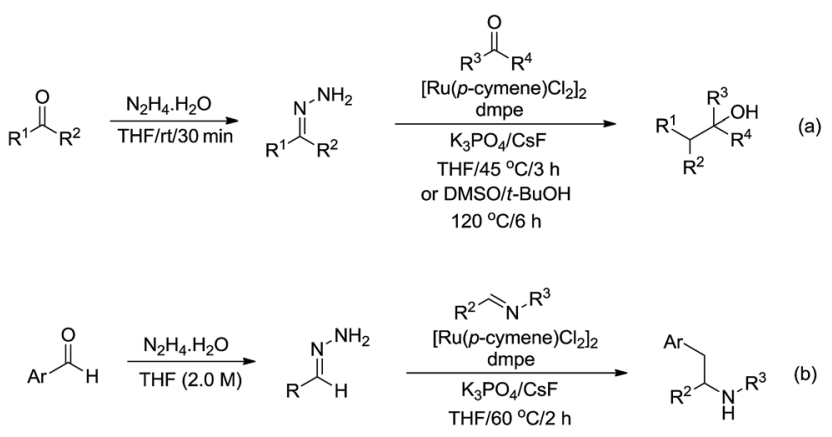

Scheme 48 Ru-catalysed nucleophilic addition of carbonyl and aryl imine compounds via hydrazone intermediate using aldehydes as carbanion equivalents.

via hydrazone intermediate that originates from naturally occurring carbonyls (Scheme 47). This strategy not only improves compatibility towards benign protic solvents and accommodates various functional groups, but also provides an opportunity for enantioselective catalysis when involving chiral ligands.

In 2017, Li and co-workers reported the ruthenium catalysed umpolung strategy for the nucleophilic addition to carbonyl ${ }^{164}$ (Scheme 48a) and aryl imine ${ }^{165}$ (Scheme 48b) compounds through hydrazone intermediates using aldehydes as carbanion equivalents. The unique chemoselectivity exhibited by carbonylderived carbanion equivalents is demonstrated by their tolerance to protic reaction media and good functional group compatibility.

Subsequently, they described a ruthenium catalysed conjugate additions via hydrazone approach, in which water was tolerated in the transformation (Scheme 49). ${ }^{166}$

Recently, $\mathrm{Li}$ and coworkers reported a nickel-catalysed $\mathrm{C}\left(\mathrm{sp}^{2}\right)-\mathrm{C}\left(\mathrm{sp}^{3}\right)$ cross-coupling reaction from two sustainable biomass-based feedstocks: phenol derivatives with umpolung aldehydes through moisture/air-stable hydrazones intermediate generated in situ (Scheme 50). ${ }^{167}$ Water tolerance, functional group compatibility and late-stage elaboration of complex

$$
\begin{aligned}
& R^{3}{ }^{R^{4}}
\end{aligned}
$$

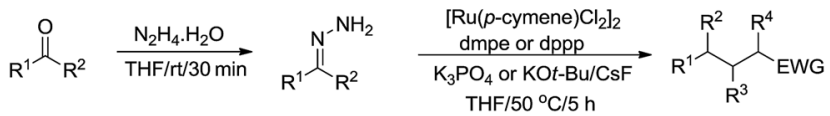

Scheme 49 Ruthenium-catalysed conjugate additions via hydrazone intermediate.

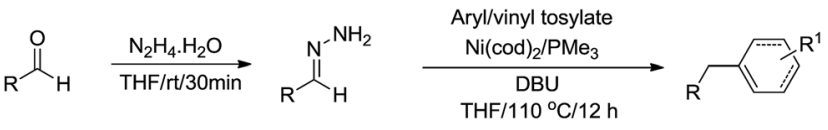

Scheme 50 Nickel-catalysed $\mathrm{C}\left(\mathrm{sp}^{2}\right)-\mathrm{C}\left(\mathrm{sp}^{3}\right)$ cross-coupling reaction via hydrazone intermediate.

biological molecules exemplified its practicability and unique chemoselectivity over stoichiometric organometallic reagents. Further development of such reactions in water is foreseen and being actively pursued in our lab.

\section{Conclusions}

The past few decades have witnessed the rapid development of water-based organic synthesis, in which the organometallic reactions in water has also made considerable progress. This article aims to summarize the key approaches for realizing the various organometallic reactions focusing on nucleophilic additions in aqueous media, which provides the readers with perspectives for further developments in this field. In view of future sustainability, the use of renewable biomass-based feedstocks constitutes an important part for sustainable development of chemical industry. The development of efficient organometallic reactions in water provides important tools for the direct conversion of biomass-derived feedstocks into highvalued chemicals and direct modification of biomolecules under native aqueous environment, and constitutes overall synthetic efficiency.

\section{Conflicts of interest}

The authors declare no competing interests.

\section{Acknowledgements}

We are grateful to the Canada Research Chair Foundation (to C.J. L.), the Canadian Foundation for Innovation, FRQNT Centre in Green Chemistry and Catalysis, and the Natural Science and Engineering Research Council of Canada for support of our researches.

\section{Notes and references}

1 R. V. Hoffman, in Organic Chemistry: An Intermediate Text, John Wiley \& Sons, Inc., 2nd edn, 2004, ch. 8.

2 E. von Frankland, Liebigs Ann., 1849, 71, 171-213.

3 E. W. Abel, F. G. A. Stone and G. Wilkinson, Comprehensive Organometallic Chemistry II: A Review of the Literature 19821994, Pergamon, Oxford; New York, 1995.

4 D. M. P. Mingos and R. H. Crabtree, Comprehensive Organometallic Chemistry III, Elsevier, Amsterdam, Boston, 2007.

5 P. Knochel and I. Wiley, Handbook of Functionalized Organometallics: Applications in Synthesis, Wiley-VCH, Weinheim, 2005. 
6 D. H. B. Ripin, in Practical Synthetic Organic Chemistry, ed. S. Caron, 2011, ch. 12.

7 R. Chinchilla, C. Nájera and M. Yus, Chem. Rev., 2004, 104, 2667-2722.

8 S. Reformatsky, Ber. Dtsch. Chem. Ges., 1887, 20, 1210-1211.

9 P. Barbier, C. R. Acad. Sci., 1899, 128, 110.

10 V. Grignard, C. R. Acad. Sci., 1900, 130, 1322.

11 H. Gilman, R. G. Jones and L. A. Woods, J. Org. Chem., 1952, 17, 1630-1634.

12 M. J. Harvey, in Alkali Metals: Organometallic Chemistry, Encyclopedia of Inorganic and Bioinorganic Chemistry, 2014.

13 B. C. G. Söderberg, Coord. Chem. Rev., 2008, 252, 57-133.

14 R. F. Heck, Acc. Chem. Res., 1979, 12, 146-151.

15 E.-I. Negishi, Angew. Chem., Int. Ed., 2011, 50, 6738-6764.

16 A. Suzuki, Angew. Chem., Int. Ed., 2011, 50, 6722-6737.

17 R. H. Grubbs, Angew. Chem., Int. Ed., 2006, 45, 3760-3765.

18 R. R. Schrock, Angew. Chem., Int. Ed., 2006, 45, 3748-3759.

19 Y. Chauvin, Angew. Chem., Int. Ed., 2006, 45, 3740-3747.

20 W. S. Knowles, Adv. Synth. Catal., 2003, 345, 3-13.

21 N. Ryoji, Angew. Chem., Int. Ed., 2002, 41, 2008-2022.

22 K. B. Sharpless, Angew. Chem., Int. Ed., 2002, 41, 2024-2032.

23 W. Keim, Fossil Feedstocks-What Comes After?, SpringerVerlag, Berlin Heidelberg, 2014.

24 M. Z. Jacobson, Air Pollution and Global Warming: History, Science, and Solutions, Cambridge University Press, 2nd edn, 2012.

25 M. Z. Jacobson, Energy Environ. Sci., 2009, 2, 148-173.

26 R. A. Sheldon, Green Chem., 2014, 16, 950-963.

27 F. Cherubini, Energy Convers. Manage., 2010, 51, 1412-1421.

28 J. H. Clark, J. Chem. Technol. Biotechnol., 2007, 82, 603-609.

29 C.-J. Li, Green Chem., 2016, 18, 1836-1838.

30 B. M. Trost, Science, 1991, 254, 1471-1477.

31 R. A. Sheldon, Chem. Tech., 1994, 24, 38-47.

32 P. A. Wender, V. A. Verma, T. J. Paxton and T. H. Pillow, Acc. Chem. Res., 2008, 41, 40-49.

33 A. L. Allred, J. Inorg. Nucl. Chem., 1961, 17, 215-221.

34 G. van Meer, D. R. Voelker and G. W. Feigenson, Nat. Rev. Mol. Cell Biol., 2008, 9, 112.

35 X. Cui, S. Mao, M. Liu, H. Yuan and Y. Du, Langmuir, 2008, 24, 10771-10775.

36 A. Chanda and V. V. Fokin, Chem. Rev., 2009, 109, 725-748.

37 R. N. Butler and A. G. Coyne, Org. Biomol. Chem., 2016, 14, 9945-9960.

38 Y. Jung and R. A. Marcus, J. Am. Chem. Soc., 2007, 129, 54925502.

39 C.-J. Li and T. H. Chan, Organic Reactions in Aqueous Media, John Wiely \& Sons, New York, 1997.

40 C.-J. Li, Chem. Rev., 2005, 105, 3095-3166.

$41 \mathrm{~F}$. A. Cotton and G. Wilkinson, Advanced Inorganic Chemistry: A Comprehensive Text, Wiley, New York, 1980.

42 W. Peters, Ber. Dtsch. Chem. Ges., 1905, 38, 2567.

43 K. Sisido, Y. Takeda and Z. Kinugawa, J. Am. Chem. Soc., 1961, 83, 538-541.

44 K. Sisido, S. Kozima and T. Hanada, J. Organomet. Chem., 1967, 9, 99-107.

45 K. Sisido and S. Kozima, J. Organomet. Chem., 1968, 11, 503513.
46 J. Nosek, Collect. Czech. Chem. Commun., 1964, 29, 597-602.

47 J. Nokami, J. Otera, T. Sudo and R. Okawara, Organometallics, 1983, 2, 191-193.

48 C.-J. Li and T. H. Chan, Tetrahedron Lett., 1991, 32, 70177020.

49 T.-P. Loh, Q.-Y. Hu, Y.-K. Chok and K.-T. Tan, Tetrahedron Lett., 2001, 42, 9277-9280.

50 X.-H. Yi, Y. Meng and C.-J. Li, Chem. Commun., 1998, 449450.

51 X.-H. Yi, Y. Meng, X.-G. Hua and C.-J. Li, J. Org. Chem., 1998, 63, 7472-7480.

52 M. B. Isaac and T.-H. Chan, J. Chem. Soc., Chem. Commun., 1995, 1003-1004.

53 T. M. Mitzel, C. Palomo and K. Jendza, J. Org. Chem., 2001, 67, 136-145.

54 L. W. Bieber, E. C. Storch, I. Malvestiti and M. F. da Silva, Tetrahedron Lett., 1998, 39, 9393-9396.

55 C.-J. Li and Y. Meng, J. Am. Chem. Soc., 2000, 122, 95389539.

56 T. Huang, Y. Meng, S. Venkatraman, D. Wang and C.-J. Li, J. Am. Chem. Soc., 2001, 123, 7451-7452.

57 C.-J. Li, Tetrahedron, 1996, 52, 5643-5668.

58 L. Rodolfo, C. Oscar, B. Joan, O. Modesto and L. F. Javier, Eur. J. Org. Chem., 2001, 3719-3729.

59 D. Backhaus, Tetrahedron Lett., 2000, 41, 2087-2090.

60 J. S. Yadav and C. Srinivas, Tetrahedron Lett., 2002, 43, 38373839.

61 A. Jeevanandam and Y.-C. Ling, Tetrahedron Lett., 2001, 42, 4361-4362.

62 T. H. Chan and C.-J. Li, J. Chem. Soc., Chem. Commun., 1992, 747-748.

63 A. Dondoni, P. Merino and J. Orduna, Tetrahedron Lett., 1991, 32, 3247-3250.

64 D. M. Gordon and G. M. Whitesides, J. Org. Chem., 1993, 58, 7937-7938.

65 E. Kim, D. M. Gordon, W. Schmid and G. M. Whitesides, J. Org. Chem., 1993, 58, 5500-5507.

66 J. Gao, R. Haerter, D. M. Gordon and G. M. Whitesides, J. Org. Chem., 1994, 59, 3714-3715.

67 M. D. Chappell and R. L. Halcomb, Org. Lett., 2000, 2, 20032005.

68 M. Warwel and W.-D. Fessner, Synlett, 2000, 865-867.

69 T. H. Chan and C.-J. Li, Organometallics, 1990, 9, 2649-2650.

70 C.-J. Li and T. H. Chan, Organometallics, 1991, 10, 25482549.

71 B. M. Trost and S. A. King, J. Am. Chem. Soc., 1990, 112, 408422.

72 Y.-Q. Lu and C.-J. Li, Tetrahedron Lett., 1996, 37, 471-474.

73 C.-J. Li, D.-L. Chen, Y.-Q. Lu, J. X. Haberman and J. T. Mague, J. Am. Chem. Soc., 1996, 118, 4216-4217.

74 C.-J. Li, D.-L. Chen, Y.-Q. Lu, J. X. Haberman and J. T. Mague, Tetrahedron, 1998, 54, 2347-2364.

75 C.-J. Li and D.-L. Chen, Synlett, 1999, 735-736.

76 J. X. Haberman and C.-J. Li, Tetrahedron Lett., 1997, 38, 4735-4736.

77 L. A. Paquette and T. M. Mitzel, J. Am. Chem. Soc., 1996, 118, 1931-1937. 
78 L. A. Paquette, Synthesis, 2003, 765-774.

79 F. Márquez, R. Montoro, A. Llebaria, E. Lago, E. Molins and A. Delgado, J. Org. Chem., 2002, 67, 308-311.

80 T.-P. Loh and J.-R. Zhou, Tetrahedron Lett., 1999, 40, 91159118.

81 T.-P. Loh and J.-R. Zhou, Tetrahedron Lett., 2000, 41, 52615264.

82 Y.-C. Teo, E.-L. Goh and T.-P. Loh, Tetrahedron Lett., 2005, 46, 6209-6211.

83 S. Kobayashi, N. Aoyama and K. Manabe, Chirality, 2003, 15, 124-126.

84 U. Schneider, M. Ueno and S. Kobayashi, J. Am. Chem. Soc., 2008, 130, 13824-13825.

85 T. M. Mitzel, C. Palomo and K. Jendza, J. Org. Chem., 2002, 67, 136-145.

86 D. Prajapati, D. D. Laskar, B. J. Gogoi and G. Devi, Tetrahedron Lett., 2003, 44, 6755-6757.

87 H. Miyabe, Y. Yamaoka, T. Naito and Y. Takemoto, J. Org. Chem., 2004, 69, 1415-1418.

88 C. Zhou, J. Jiang, Y. Zhou, Z. Xie, Q. Miao and Z. Wang, Lett. Org. Chem., 2005, 2, 61-64.

89 B. H. Lipshutz and S. Ghorai, Aldrichimica Acta, 2008, 41, 59. 90 M. Ueda and N. Miyaura, J. Org. Chem., 2000, 65, 4450-4452. 91 C.-J. Li, Acc. Chem. Res., 2002, 35, 533-538.

92 M. Sakai, M. Ueda and N. Miyaura, Angew. Chem., Int. Ed., 1998, 37, 3279-3281.

93 K. Fagnou and M. Lautens, Chem. Rev., 2003, 103, 169-196. 94 T. Yamamoto, T. Ohta and Y. Ito, Org. Lett., 2005, 7, 41534155.

95 S. Lin and X. Lu, J. Org. Chem., 2007, 72, 9757-9760.

96 T. Hayashi and K. Yamasaki, Chem. Rev., 2003, 103, 28292844.

97 P. Tian, H.-Q. Dong and G.-Q. Lin, ACS Catal., 2012, 2, 95119.

98 X. Lu and S. Lin, J. Org. Chem., 2005, 70, 9651-9653.

99 S. Lin and X. Lu, Org. Lett., 2010, 12, 2536-2539.

100 K. Kikushima, J. C. Holder, M. Gatti and B. M. Stoltz, J. Am. Chem. Soc., 2011, 133, 6902.

101 C.-G. Feng, M.-H. Xu and G.-Q. Lin, Synlett, 2011, 13451356.

102 C. L. Hawkins and M. J. Davies, Biochim. Biophys. Acta, Bioenerg., 2001, 1504, 196-219.

103 M. Gutowski and S. Kowalczyk, Acta Biochim. Pol., 2013, 60, 1-16.

104 H. Yorimitsu, T. Nakamura, H. Shinokubo and K. Oshima, J. Org. Chem., 1998, 63, 8604-8605.

105 H. Yorimitsu, T. Nakamura, H. Shinokubo, K. Oshima, K. Omoto and H. Fujimoto, J. Am. Chem. Soc., 2000, 122, 11041-11047.

106 C. Petrier, C. Dupuy and J. L. Luche, Tetrahedron Lett., 1986, 27, 3149-3152.

107 J. L. Luche and C. Allavena, Tetrahedron Lett., 1988, 29, 5369-5372.

108 C. Dupuy, C. Petrier, L. A. Sarandeses and J. L. Luche, Synth. Commun., 1991, 21, 643-651.

109 B. Giese, W. Damm, M. Roth and M. Zehnder, Synlett, 1992, 441-443.
110 P. Erdmann, J. Schäfer, R. Springer, H.-G. Zeitz and B. Giese, Helv. Chim. Acta, 1992, 75, 638-644.

111 J. L. Luche, C. Allavena, C. Petrier and C. Dupuy, Tetrahedron Lett., 1988, 29, 5373-5374.

112 K. Michał Pietrusiewicz and M. Zabłocka, Tetrahedron Lett., 1988, 29, 937-940.

113 M. Roth, W. Damm and B. Giese, Tetrahedron Lett., 1996, 37, 351-354.

114 R. M. Suárez, J. P. Sestelo and L. A. Sarandeses, Synlett, 2002, 1435-1438.

115 R. M. Suárez, J. Pérez Sestelo and L. A. Sarandeses, Chem.Eur. J., 2003, 9, 4179-4187.

116 T. Huang, C. C. K. Keh and C.-J. Li, Chem. Commun., 2002, 2440-2441.

117 C.-J. Li and W.-C. Zhang, J. Am. Chem. Soc., 1998, 120, 91029103.

118 H. Miyabe, M. Ueda, A. Nishimura and T. Naito, Org. Lett., 2002, 4, 131-134.

119 M. Ueda, H. Miyabe, A. Nishimura, O. Miyata, Y. Takemoto and T. Naito, Org. Lett., 2003, 5, 3835-3838.

120 C. C. K. Keh, C. Wei and C.-J. Li, J. Am. Chem. Soc., 2003, 125, 4062-4063.

121 Z.-L. Shen, Y.-L. Yeo and T.-P. Loh, J. Org. Chem., 2008, 73, 3922-3924.

122 T. H. Chan, C.-J. Li and Z. Y. Wei, J. Chem. Soc., Chem. Commun., 1990, 505-507.

123 J.-Y. Zhou, Y. Jia, Q.-Y. Shao and S.-H. Wu, Synth. Commun., 1996, 26, 769-775.

124 T. H. Chan, C.-J. Li, M. C. Lee and Z. Y. Wei, Can. J. Chem., 1994, 72, 1181-1192.

125 P. H. Lee, K. Bang, K. Lee, S.-y. Sung and S. Chang, Synth. Commun., 2001, 31, 3781-3789.

126 L. W. Bieber, I. Malvestiti and E. C. Storch, J. Org. Chem., 1997, 62, 9061-9064.

127 W. J. Chung, S. Higashiya and J. T. Welch, J. Fluorine Chem., 2001, 112, 343-347.

128 J. B. F. N. Engberts, in Methods and Reagents for Green Chemistry, ed. P. Tundo, A. Perosa and F. Zecchini, John Wiley \& Sons, Inc., NJ, 2007, ch. 7, pp. 159-170.

129 D. Torsten, P. Eckhard and O. Günther, Angew. Chem., Int. Ed., 2005, 44, 7174-7199.

130 T. Hamada, K. Manabe and S. Kobayashi, J. Am. Chem. Soc., 2004, 126, 7768-7769.

131 B. H. Lipshutz, S. Huang, W. W. Y. Leong, G. Zhong and N. A. Isley, J. Am. Chem. Soc., 2012, 134, 19985-19988.

132 B. H. Lipshutz and S. Ghorai, Aldrichimica Acta, 2012, 45, 3.

133 B. H. Lipshutz, S. Ghorai and M. Cortes-Clerget, Chem.-Eur. J., 2018, 24, 6672-6695.

134 F. Zhou and C.-J. Li, Nat. Commun., 2014, 5, 4254.

135 D. J. Lippincott, R. T. H. Linstadt, M. R. Maser, F. Gallou and B. H. Lipshutz, Org. Lett., 2018, 20, 4719-4722.

136 L. Cicco, S. Sblendorio, R. Mansueto, F. M. Perna, A. Salomone, S. Florio and V. Capriati, Chem. Sci., 2016, 7, 1192-1199.

137 G. Dilauro, M. Dell'Aera, P. Vitale, V. Capriati and F. M. Perna, Angew. Chem., Int. Ed., 2017, 56, 10200-10203. 
138 J. García-Álvarez, E. Hevia and V. Capriati, Eur. J. Org. Chem., 2015, 6779-6799.

139 J. García-Álvarez, E. Hevia and V. Capriati, Chem.-Eur. J., 2018, 24, 14854-14863.

140 R. A. Sheldon, Chem. Soc. Rev., 2012, 41, 1437-1451.

141 J.-Q. Yu, L. Ackermann and Z. Shi, in C-H Activation, Topics in Current Chemistry, Springer, Berlin, 2010, ch. 292.

142 P. H. Dixneuf and H. Doucet, in $\mathrm{C}-\mathrm{H}$ Bond Activation and Catalytic Functionalization I Topics in Organometallic Chemistry, Springer, Cham, 2015.

143 P. H. Dixneuf and H. Doucet, in $\mathrm{C}-\mathrm{H}$ Bond Activation and Catalytic Functionalization II Topics in Organometallic Chemistry, Springer, Cham, 2016.

144 C. I. Herrerías, X. Yao, Z. Li and C.-J. Li, Chem. Rev., 2007, 107, 2546-2562.

145 C. Wei and C.-J. Li, Green Chem., 2002, 4, 39-41.

146 C.-J. Li and C. Wei, Chem. Commun., 2002, 268-269.

147 C. Wei and C.-J. Li, J. Am. Chem. Soc., 2002, 124, 5638-5639.

148 C. Wei and C.-J. Li, J. Am. Chem. Soc., 2003, 125, 9584-9585.

149 (a) X. Yao and C.-J. Li, Org. Lett., 2005, 7, 4395-4398; (b) C.-J. Li, Acc. Chem. Res., 2010, 43, 581-590.

150 P. B. Arockiam, C. Fischmeister, C. Bruneau and P. H. Dixneuf, Angew. Chem., Int. Ed., 2010, 49, 6629-6632. 151 L. Ackermann and A. V. Lygin, Org. Lett., 2012, 14, 764-767. 152 M.-Z. Lu, P. Lu, Y.-H. Xu and T.-P. Loh, Org. Lett., 2014, 16, 2614-2617.
153 H. Gong, H. Zeng, F. Zhou and C.-J. Li, Angew. Chem., Int. Ed., 2015, 54, 5718-5721.

154 B. Wang, W. A. Nack, G. He, S.-Y. Zhang and G. Chen, Chem. Sci., 2014, 5, 3952-3957.

155 J. Hu, T. Lan, Y. Sun, H. Chen, J. Yao and Y. Rao, Chem. Commun., 2015, 51, 14929-14932.

156 G. Deng and C.-J. Li, Tetrahedron Lett., 2008, 49, 5601-5604.

157 D. Seebach and E. J. Corey, J. Org. Chem., 1975, 40, 231-237.

158 B.-T. GrÖBel and D. Seebach, Synthesis, 1977, 357-402.

159 S. Gustavo, Curr. Org. Chem., 2000, 4, 283-304.

160 J. Sukumaran and U. Hanefeld, Chem. Soc. Rev., 2005, 34, 530-542.

161 M. Pohl, G. A. Sprenger and M. Müller, Curr. Opin. Biotechnol., 2004, 15, 335-342.

162 R. S. Menon, A. T. Biju and V. Nair, Beilstein J. Org. Chem., 2016, 12, 444-461.

163 D. Enders and T. Balensiefer, Acc. Chem. Res., 2004, 37, 534541.

164 H. Wang, X.-J. Dai and C.-J. Li, Nat. Chem., 2016, 9, 374-378.

165 N. Chen, X.-J. Dai, H. Wang and C.-J. Li, Angew. Chem., Int. Ed., 2017, 56, 6260-6263.

166 X.-J. Dai, H. Wang and C.-J. Li, Angew. Chem., Int. Ed., 2017, 56, 6302-6306.

167 L. Lv, D. Zhu, J. Tang, Z. Qiu, C.-C. Li, J. Gao and C.-J. Li, ACS Catal., 2018, 8, 4622-4627. 